sphere, the northermost population just reaching the equator at the Galapagos. Only three species nest entirely in ice and snow. The biggest known colony is of ten million chinstraps recently reported from Zavodovski Island in the South Sandwich group. These are just a few of the fascinating facts that emerge. Another is that, up to 1947, only two emperor colonies were known to science. In the last 20 years another 18 have been found. One of them was discovered by the author, but by a stroke of irony this very colony - and only this one - is not marked on the distribution map on page 20 .

But this is the tiniest of blemishes in an absolutely excellent little book, well worth the guinea asked. On a month's trip to Chile and the Antarctic I found it a useful, colourful, readable and succinct summary of our knowledge of this family.

JEFFERY BOSWALL

\title{
Thorburn's Birds edited with an introduction and new text by James Fisher. Ebury Press and Michael Joseph, 50s. \\ Birds of Australia 2 Vols and Birds of Europe 2 Vols, by John Gould, text by Abram Rutgers. Methuen, 35s. each volume.
}

To a young student of painting, one of the great discoveries is the sudden ability to recognise the work of an artist without reading the signature. Among my first was Archibald Thorburn. His four-volume British Birds in the school library became a sort of bible to me. His integrity and accuracy were so great in my eyes that if I happened to see a wild bird that differed in some small way from the Thorburn illustration, I supposed without question that I had seen some sort of freak. Now that I have looked at all these familiar pictures again the veneration still persists even though many skilled modern painters have extended the tradition with their own original and welcome interpretations.

Thorburn's birds had feathers on. One could sense how they would feel to the touch and how different that would be from the textures of their background rock, mud, sand or tree bark. Yet like so many painters before and since his sketchbooks were often more exciting than his finished work.

Thorburn must surely be the greatest illustrator of birds this country has ever produced - a sort of British answer to Audubon, a scientifically-minded genius with a great sense of the decorative, a certainty of hand and a complete mastery of his medium. But there is a paradox that seems to date him by reflecting not just his own attitude but that of his period's ornithologists towards the birds they studied. The essential and peculiar capability of birds is flight, yet scientists avoided this aspect of bird movement as strenuously as Thorburn avoided it in his pictures. When he took the plunge he seemed out of his depth as though he knew full well he were attempting something neither he nor his contemporaries fully understood. Perspective often went wild. The feathers on the outstretched wings were feathers indeed but seldom were they feathers that now supported a body aloft or responded to the aerodynamic forces of the moment.

That such skill and understanding should have missed these things makes him a tradition and an era in one and sets Archibald Thorburn as a great milestone in the broadening treatment of birds as subjects to paint. James Fisher's new text has transformed the four-volume collector's item into a modern reference book on bird status and distribution while re-presenting all the wealth of the original plates. One may now call off the search for second-hand copies of British Birds; if one ignores sentiment, Thorburn's Birds is much more useful and costs only 50s. 
Audubon to Thorburn with John Gould between is a sort of artistic progression, and I believe one can see this more clearly from today's standpoint where there has never been such variety, richness, freedom or for that matter, skill, in the history of wildlife painting. These three great names formed a bridge between an artist's main function of providing what a camera later gave us to the less fettered purpose of painting what he saw and enjoyed in the way he personally felt it should be interpreted.

Gould had less of Audubon's flamboyant design but more than Thorburn. His was a gentler form of portrayal yet there was still a little of the fantasy which Thorburn never attempted. The shotgun naturalist was looking through a glass and the life he saw was stronger than imagination. There came the sort of emergence of reality one might expect from a student of figure drawing who had just discovered a cosy model after years of anatomical study in the morgue. In terms of art this is no criticism. Inspiration comes in many ways. That such beauty as Gould created should come from so many corpses seems to mitigate the slaughter - especially when one considers the abundance of wildlife in his day and the present-day chances of spreading the enjoyment of his work among so many through books such as these.

The four volumes, each of which covers 80 species, make no pretence to being definitive handbooks; they are folios of Gould's work. The supporting text by Dutch ornithologist Abram Rutgers is brief, up-to-date fact written in a manner that makes them books for reading rather than reference, and its presentation is a reminder that well-set type is the best of all foils to decorative drawing. The combination of the two makes these books lasting tributes to a great master of bird painting.

KEITH SHACKLETON

\section{South America and Central America by Jean Dorst. Random}

House, New York, \$20. Hamish Hamilton, London, 105s.

To condense an account of the natural history of this immense continent into the covers of one book - even with 290 pages measuring almost 12 inches by 10 inches - and make it meaningful is no mean feat, and it is triumphantly achieved by the author of this sumptuous and very readable book, excellently translated from the French. Not only is this the most diverse continent, ranging from the equatorial tropics to the Antarctic ice, with some of the world's most massive mountain ranges, greatest deserts (high and cold, low and hot), longest rivers, most extensive tropical jungles, vastest plains, and a group of islands, the Galapagos, that are one of the natural wonders of the world, it is also, despite all the destruction man has wreaked on it, a naturalists' paradise compared with other continents. In Colombia alone there are 1556 species of birds - compared with 691 for the whole of North America up to the Arctic.

Jean Dorst achieves his task by relating the wild life to the major habitats, which he treats in turn, from the tropical islands of the West Indies to the 'glaciers, lakes and dismal straits' of Patagonia and Tierra del Fuego and the albatrosses and elephant seals of Antarctica; he shows how the wildlife has adapted itself to even the most inhospitable of homes - like the cave-dwelling birds on the treeless, cold, windswept high plateaus of Peru, some of which dig their own burrows, using their beaks as a pickaxe and their claws as a shovel to scoop the earth away, where the plants are stunted and anchored against the winds by powerful root systems, and the vicuna and the llama have an enormously high red corpuscle count in their blood. His text abounds in vivid descriptions, and even with this immense canvas to cover he finds space to describe a hummingbird building its nest and tell the story of the sixteenth-century 